\title{
Ergonomic Analysis of Traditional Pine Oleoresin Tapping: Musculoskeletal Disorders, Cumulative Fatigue, and Job Satisfaction
}

\author{
By: \\ Efi Yuliati Yovi*, Nadya Amanda \\ Department of Forest Management, Faculty of Forestry and Environment, IPB University. Jl. Raya Dramaga, \\ Bogor 16680, West Java, Indonesia \\ *E-mail: eyyovi@apps.ipb.ac.id
}

\begin{abstract}
Pine oleoresin is a valuable non-timber forest product commodity in Indonesia. A traditional tapping using small-sized hoes ("kadukul" in Sundanese or "pethel" in Javanese) are widely applied. Given the protection of occupational safety and health is a worker's right, various ergonomic issues were discussed in this study. Musculoskeletal disorders (MSDs) was examined by using Standardized Nordic Questionnaire and Wong-Baker Pain Rating Scale instruments, physical-mental-social fatigue was measured by Cumulative Fatigue Symptoms Index (CFSI), and job satisfaction was tested from eight variables such as wage, employment status, accessibility, health service, living facilities, work equipment, training, and social facility. This study revealed that most of the workers suffered from intense MSDs in the shoulder, arm, wrist, hand, thigh, calf, and foot (mostly right body side). This finding was in line with the CFSI analysis. The common fatigue symptoms suffered by the workers were in the category of the physical dimension, such as in sub-dimensions of general fatigue, chronics fatigue, and physical disorder. The job satisfaction analysis confirmed that two variables, i.e., wage and employment status, influenced job satisfaction significantly in a positive association. Proper personal protective equipment and workaid, working techniques improvement that meets occupational safety and health standard, and safety behavior incentive should be considered as effective strategies in improving the worker's safety and health protection.
\end{abstract}

Keywords: forest harvesting, forestry worker, non-timber forest product, physical fatigue, safety

\section{INTRODUCTION}

Forest product harvesting refers to extracting forest products from the forest to the market place for a benefit value. Due to the type of commodity, resources, and social context, forest product harvesting activities in Indonesia are carried out at various levels of technological application, ranging from the conventional or manual system (labor-intensive) to semimechanical system (Yovi and Andriyani 2019). Regardless of the level of technology used, this operation has a high-risk that may threaten the worker's occupational safety and health (Lindroos and Burström 2010; Potočnik et al. 2009; Tsioras et al. 2014; Yovi 2019; Yovi and Yamada 2019).

Pine oleoresin extraction is one form of forest product harvesting, specifically from pine tree (Pine sp.). Pine oleoresin is a valuable non-timber forest product commodity in Indonesia. The estimation of total pine stands was around 126,666 ha (BPS 2016). In 2017, pine oleoresin production reached 77,706 tons, 1.7 times higher than 2010 production (45,689 tons only) (BPS 2011, 2018). 
Despite the lack of accurate data, traditional tapping tools such as small-sized hoes ("kadukul" in Sundanese or "pethel" in Javanese) has been widely applied for the tapping activities. Body movements in this traditional oleoresin tapping technique are categorized as manual material handling activity (Kumar 2001; Sakka et al. 2015). Manual handling is closely associated with musculoskeletal disorders (MSDs) (Chaffin et al. 2006; Yovi and Prajawati 2015). Musculoskeletal disorders (MSDs) are diseases or disorders of the soft tissues of the muscles, joints, ligaments, tendons, cartilage, and the nervous system (Chaffin et al. 2006). In America, MSDs are better known as cumulative trauma disorders (CTD), while in the UK and Australia are called repetitive strain injuries (RSI). Parts of the body that are usually affected by MSDs are the spine, legs, and shoulders (Huysamen et al. 2018). Whereas, all of this is body segment mostly used for manual material handling work (Collins and O'Sullivan 2015) such as pine collecting work.

Reports of fatalities in the oleoresin extraction are rarely found. Yovi and Yamada (2019) stated that the accident case with fatality in tapping activity was around 1 case per year from 2008-2015, which is the lowest below other forest management activities. However, given the protection of occupational safety and health is a worker's right that must be fulfilled, an ergonomics study on oleoresin extraction is still needed. In the long term, functional occupational safety and health protection of the workers is one crucial support for sustainable forest management. Ergonomics evaluation in terms of workload and the appropriate duration and frequency of resting in the oleoresin extraction activities had been carried out by ( et al. (2005). In extend, a comprehensive ergonomics evaluation on oleoresin is required to grab a complete picture of the ergonomics problems. Therefore, this research explored ergonomic issues on MSDs, physical-mental-social fatigue, and job satisfaction in traditional tapping of pine oleoresin.

\section{MATERIALS AND METHODS}

This research was conducted in a plantation forest in Sukabumi, West Java, Indonesia, from February to March 2020. Thirty respondents -randomly selected-participated in this study. It should be noted that: (1) the process and stages of the pine oleoresin extraction in this study represents the traditional extraction method carried out in Indonesia, and (2) the characteristics of respondents involved in this study also represent the majority of pine oleoresin tapping workers in Indonesia. Therefore, even though the number of respondents involved was only 30 people, the information captured from this study offered sufficient elements to grab a generic picture on ergonomics conditions of the pine oleoresin extraction from pine tree (Pinus merkusii Jungh. \& de Vriese).

\section{Musculoskeletal disorders (MSDs)}

MSDs issue was investigated by using the Standardized Nordic Questionnaire (SNQ) instrument. Different people may feel musculoskeletal pain in different parts of the body even though they perform similar physical activity. However, the SNQ questionnaire has high accuracy in capturing MSDs complaints that are likely experienced by sedentary workers (Kuorinka et al. 1987). This instrument has been widely applied in different discipline from human health and social assistance, agriculture, livestock, forestry, computer, teaching, commercial activities, and other (López-Aragón et al. 2017).

Since the musculoskeletal system in the human body works as a complex mechanism, a modification was performed on the SNQ, especially on the questions related to body parts and recall periods. Most body postures are generated by a complex mechanism work of agonist, antagonist, and synergist muscles located differently in dorsal and ventral sections (coronal 
plane) of the human body (Chen et al. 2017). Therefore, we added the front and backside version in the SNQ questionnaire to differentiate the pain locations according to the coronal plane. The SNQ data was taken through in-depth interviews by always ensuring that respondents only point to the pain caused by the tapping work, not from other physical activities. In the term of recall period, the frequency of the symptoms was not asked to avoid complexity perception during data collection. Instead, pain intensity data was taken. The pain was measured based on selfreport using the Wong-Baker pain rating scale (WBS). The WBS has been used for the children's population as it is easy to understand and has been widely used in the diverse adult population (Garra et al. 2010). In this study, the respondent chose the face that best describes their level of pain. We modified the scale into a 0-5 pain scale. An explanation of each scale was given to the respondent before data collection to avoid misperceptions in the level selection. The pain level 0 refers to "no hurts" in which respondents feel perfectly normal. Pain level 5 refers to "hurts worst".

\section{Cumulative fatigue}

Cumulative fatigue was measured by using the Cumulative Fatigue Symptoms Index (CFSI) (Kosugo et al. 1992). CFSI is a questionnaire that contains "yes" or "no" answers reflecting three dimensions of fatigue (physical fatigue, mental fatigue, and social fatigue). The three dimensions are classified into eight sub-dimensions with 75 questions (Table 1) (Yoshimura and Acar 2004). The Indonesian version of the questionnaires is available in Yovi (2019). The equation for each question is:

$$
r=\frac{y}{T}
$$

where $r$ indicates the complaint rate for each question, $y$ indicates the total "yes" answer within each question, and $T$ indicates the total number of respondents involved. The equation for each group is:

$$
R=\frac{Y}{k T}
$$

where $R$ indicates the complaint rate for each group, $Y$ indicates the total "yes" answer within each group, $T$ indicates the total number of respondents involved, and $k$ indicates the number of questions in each group.

Table 1. Description of the Cumulative Fatigue Symptom Index (originated from Kosugo and Fujii 1987).

\begin{tabular}{|l|c|l|}
\hline Type of fatigue & $\begin{array}{c}\text { Number of } \\
\text { questions }\end{array}$ & \multicolumn{1}{|c|}{ Scope of questions } \\
\hline Physical fatigue & 10 & $\begin{array}{l}\text { The questions cover items on carelessness, feeling weak, } \\
\text { dizzy, and tiring eyes. Respondents were also questioned } \\
\text { whether they have a backache, shoulder stiffness, and } \\
\text { tired legs. Included in this question is whether } \\
\text { respondents are slept well or not. }\end{array}$ \\
\hline Chronic fatigue & 8 & $\begin{array}{l}\text { The questions cover symptoms related to tiredness such } \\
\text { as too sleepy, feeling tired all the time so that they feel } \\
\text { like lying down during work, lacking energy, and not } \\
\text { recover from the previous fatigue. }\end{array}$ \\
\hline Physical disorders & 7 & $\begin{array}{l}\text { The questions cover items on the common symptom of a } \\
\text { physical disorder, such as loss of appetite, difficulty } \\
\text { falling asleep, problem on the digestive system, diarrhea, } \\
\text { heavy head, and excessive worry about their health. }\end{array}$ \\
\hline
\end{tabular}




\begin{tabular}{|c|c|c|}
\hline Type of fatigue & $\begin{array}{c}\text { Number of } \\
\text { questions }\end{array}$ & Scope of questions \\
\hline \multicolumn{3}{|c|}{ Psychological fatigue } \\
\hline $\begin{array}{l}\text { Depressive } \\
\text { feelings }\end{array}$ & 9 & $\begin{array}{l}\text { The questions cover items on the typical symptoms that } \\
\text { reflecting a mental dimension of fatigue especially } \\
\text { depressive feeling, e.g., feeling gloomy, hate their self, } \\
\text { can enjoy nothing, no fun in their life, tend to be a loner } \\
\text { (or in contrary), and want to have a party and let loose. }\end{array}$ \\
\hline Feeling of anxiety & 11 & $\begin{array}{l}\text { The questions were given to measure the mental } \\
\text { dimension of fatigue, especially those related to "feeling } \\
\text { of anxiety" symptoms, e.g., feeling worried, uneasy, } \\
\text { restless, difficulty in focusing or concentrating, and } \\
\text { feeling inferior. }\end{array}$ \\
\hline $\begin{array}{l}\text { Decrease in } \\
\text { vitality }\end{array}$ & 9 & $\begin{array}{l}\text { The questions measure fatigue's mental dimension, } \\
\text { especially in the aspect of decrease of vitality cover items } \\
\text { to reveal their impatience, laziness, and ability to give full } \\
\text { attention to work. The respondents also questioned } \\
\text { whether they are feeling troublesome, lose vitality, and } \\
\text { dull minds or not to measure the decrease vitality level. }\end{array}$ \\
\hline \multicolumn{3}{|l|}{ Social fatigue } \\
\hline Irritability & 7 & $\begin{array}{l}\text { All the questions are about whether the respondents } \\
\text { quickly get angry or not, feel tense or not, and feel } \\
\text { irritated for no reason. Including in the questions is } \\
\text { whether respondents have a feeling to beat someone up } \\
\text { or not. The issues were given to measure the social } \\
\text { dimension of fatigue, especially in "irritability" } \\
\text { symptoms. }\end{array}$ \\
\hline $\begin{array}{l}\text { Unwillingness to } \\
\text { work }\end{array}$ & 13 & $\begin{array}{l}\text { The questions cover items on the typical symptom of } \\
\text { social dimension fatigue, especially unwillingness to } \\
\text { work, e.g., feel unsatisfied with their work, feel their } \\
\text { work is too monotonous, relationship with boss or } \\
\text { colleague. }\end{array}$ \\
\hline
\end{tabular}

Adopted from Yoshimura and Acar (2004).

\section{Job satisfaction}

Job satisfaction was analyzed through a questionnaire exploring potential variables that potentially affect job satisfaction. Eight independent variables were tested in this study, i.e., wage, employment status, accessibility, health service, living facility, work equipment, training, and social facility (Yovi and Yamada 2019). The attributes used in this study were binary ( atisfied $=1$; dissatisfied $=0$ ). Spearman Rank test was used to see the association of each dependent variable to job satisfaction.

\section{RESULTS AND DISCUSSION}

\section{Respondents characteristics and the nature of oleoresin tapping work}

All respondents were married, with an average age of 46 years ( $22-75$ years). The average number of dependent family members is four people (2-8 family members). Almost $83 \%$ of respondents had low levels of education (elementary school graduates). Their status is a 
seasonal worker with pine tapping as their second job. This work provides a stable additional income during the dry season.

On average, respondents have been in this job for more than 20 years. Their other economic activities are farming (dominant), running a small grocery shop, or breeding farm animals. The percentage of income contribution from oleoresin tapping to their monthly income is $50 \%$ (Figure 1 ). The average monthly income from tapping activities is IDR 1,680,0000 (IDR $600,000-3,800,000$ ), make the average total monthly income is IDR 3,392,000 (IDR $1,683,677-6,509,192)$. As many as $73 \%$ of respondents have a total income above the Sukabumi District's minimum wage.

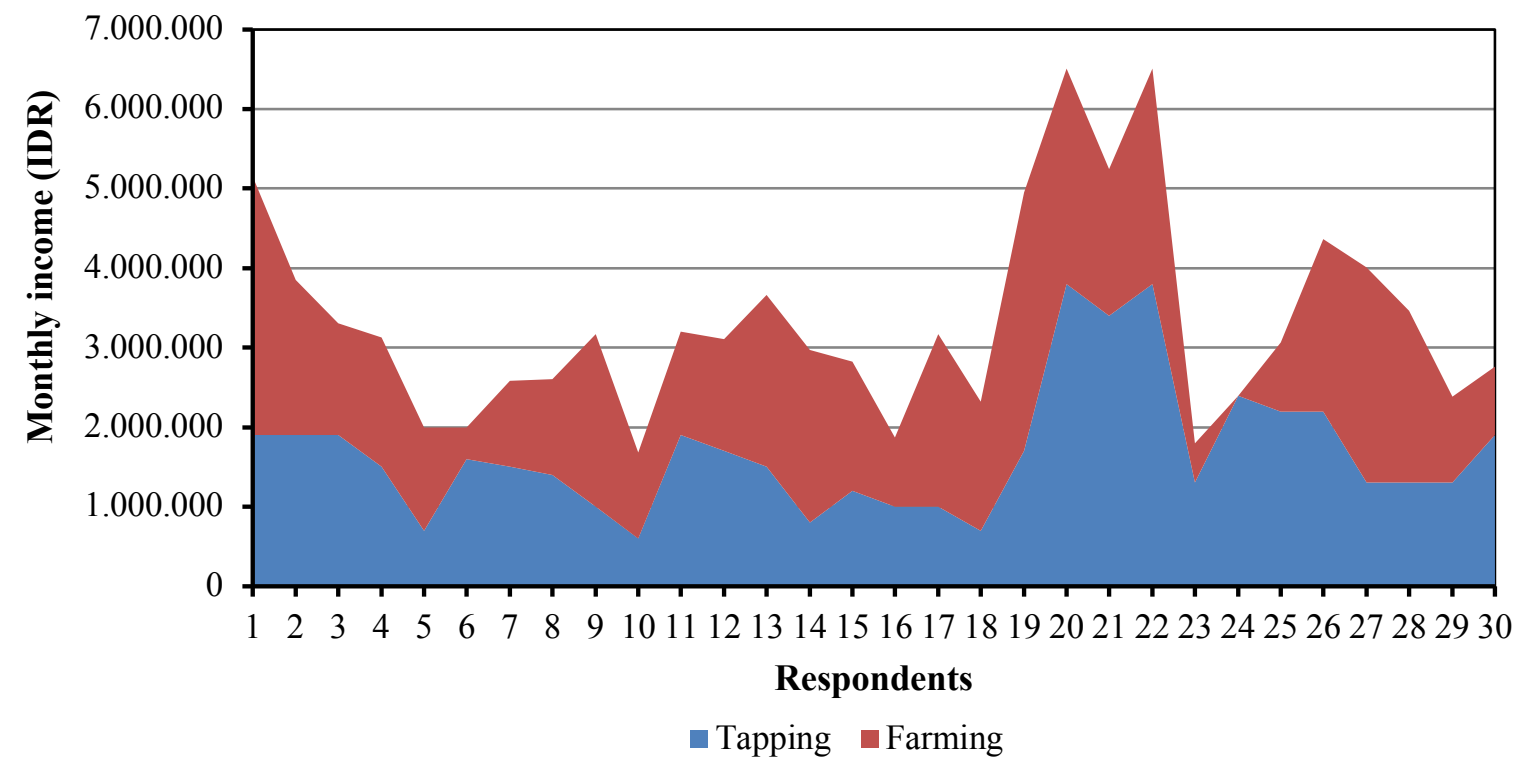

Figure 1. Monthly income of pine oleoresin tapping versus other jobs.

The extraction of pine oleoresin consists of bark removal activity (usually called as "refreshing") and oleoresin collecting activity. Refreshing is carried out periodically (usually once in three days) to expose the resin canal in secondary xylem. Oleoresin collecting is carried once in 10 days period. In this study, a worker can do the refreshing activity to 100-120 trees per day (with two cut surfaces per tree; it makes 200-240 bark removal replications).

Tapping usually started at 6:00 a.m. and ended at around 2:00 p.m. (about 6-7 hours effective). There are various traditional extractions methods, i.e., Chinese method (the downward-pointing V-shape groove), American method (horizontal groove), Hugues or French method (in Indonesia usually called quare), and Mazek or rill method (V-shaped groove) (Cunningham 2012). The Hugues/French method/quare is the most dominant extraction method in Indonesia (Figure 2a). In this technique, slices of around $10 \mathrm{~cm}$ wide are cut (by using small hoe/kadukul/pethel) into the trunk, reaching the secondary xylem. Kadukul has a slightly curved sharp edge (Figure 2b) with a total length of about $18 \mathrm{~cm}$, the width of the blade is 5.5 $\mathrm{cm}$ and weight $0.5 \mathrm{~kg}$. The cut surface/wound position varied considerably at the study site, ranging from $10 \mathrm{~cm}$ up to $3 \mathrm{~m}$ above the ground.

A stimulant (usually strong acidic liquid, either organic or non-organic) is applied in the freshly wounded exposed surface after a new wound is made. This strong acidic liquid will provide a heating effect so that the oleoresin lasts in liquid condition. This liquid can cause eye irritation if contact occurs. Many of the stimulants are toxic that inhaling spray particles can cause respiratory problems (Guan et al. 2016). 
Based on the work's characteristics, personal protective equipment (PPE) such as safety shoes, gloves, safety helmets, safety glasses or visors, and masks, are needed. Safety shoes will prevent direct contact with hazard sources such as slippery and uneven forest ground, venomous animals (e.g., snakes), and slippery stairs. Safety shoes should be light boots with anti-slip rubber sole. Rubber grid gloves are needed for better hand coupling. Gloves are also needed to prevent injured hands from touching the rough surface of the bark. Safety helmets are mandatory PPE when working under forest stands because pine fruit or dried twigs can fall. Although the size is quite small and light, falling from a height causes these light objects to posses significant kinetic energy due to its motion. This kinetic energy can cause injury when falling on the bare head. Safety glasses/visors are needed to protect the eyes against small pine bark flakes and splashes of strong acidic liquid. The mask is used to avoid small chemical particles of strong acidic liquid being inhaled (Guan et al. 2016).
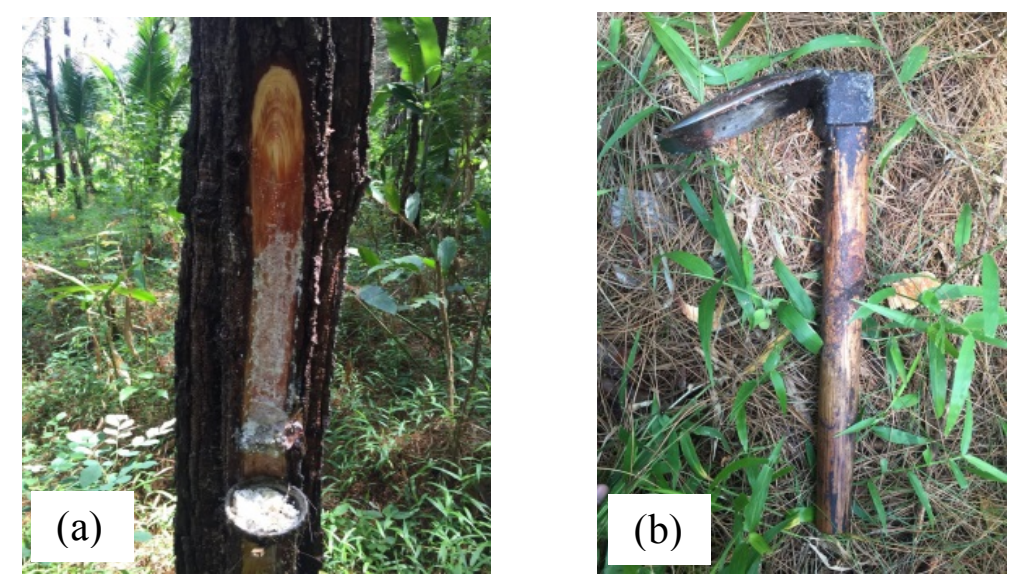

Figure 2. (a) The wound shape on the Hugue/French/quare technique and (b) the traditional tapping tool (kadukul/pethel).

However, during the observation, most of the workers did not use proper and complete PPE. None of the workers wore safety helmets, the majority $(83 \%)$ only wore cloth hats that were considered a sufficient substitute for helmets, and the rest (17\%) work bareheaded. Masks were used by only $10 \%$ of workers, and gloves were used by $43 \%$ of workers for the reason of feeling discomfort. No workers wore visor even though there were accidents causing eye injury due to bark flakes splitting.

Depth interview reveals there were seven accidents cases during 2006-2012: six cases were in the form of hit by the tip of the kadukul/pethel's blade (six cases, causing 148 lost workdays, ranged from 14-30 working days lost, parts of the body injured were the forearm, right thigh, right knee, and right foot) and one case was in the form of a hit by a splinter of pine barks (caused two working days lost). In the interview, the near-miss incidents were not being counted. Work accidents will increase ineffective work time, which will reduce overall work productivity. Experienced injured respondents admitted that work accidents occurred because they were not careful and not wear proper PPE. These statements indicate that unsafe actions (e.g., careless and inadvertent, disobey the rules, break the standard of work procedures, do not wear PPE, and keep working in unwell health conditions) mostly triggered the work accidents in oleoresin extraction, although indirectly, work equipment used and natural conditions also may contribute to the accidents (Wiegmann et al. 2005). 


\section{Standardized Nordic Questionnaire}

In Indonesia, the issue of MSDs has not been taken seriously. In Indonesia, data on economic losses due to MSDs are not yet available, but in America, the financial costs of MSDs reach USD 2.6 billion per year (Bhattacharya 2014). MSDs may result in severe health problems that cost not only to economic distress due to medical expenses or low work productivity (Karwowski and Marras 2003) but also reduce the quality of life of the sufferers (Kahraman et al. 2016). For seasonal workers with a straight work rate payment system, a decrease in workability will directly result in a reduction of income (Hrymak and Pérezgonzález 2007). In the end, this situation will ultimately harm the company's performance.

The SNQ shows that the parts of the body with the highest level of pain were the right shoulder and upper arm (for dorsal dan ventral sections) and the right forearm and wrist (ventral section) (Figure 3). High intensity in using the right hand during refreshing, especially when the tapping height is above the worker's shoulder, was suspected to be the trigger. Muscle work is getting heavier as workers also often using an awkward posture (Figure 4). Field observations confirmed that this movement is carried out hundreds of times a day. As a result, the right muscles receive more pressure due to the continuous workload, repetitive movements, and awkward posture that accelerates the decrease in muscular endurance (Chaffin et al. 2006; Ferguson et al. 2013; Hansen et al. 2012).

MSDs were also reported in the right and left legs (thighs, back of the knee, and calf, Figure 3) because the worker also works in a squatting position (Figure 4). The WBS results (Figure 5) also verified that squatting posture potentially triggers excessive pressure on the vertebrae, resulting in musculoskeletal injury and chronics low back pain (Kroemer and Grandjean 1997; Kumar 2001; Sakka et al. 2015; Yovi and Andriyani 2019).

The location of MSDs complaints in this study is very different from the results of a similar study in chainsaw-use logging activities (Yovi and Yamada 2019). Chainsaw operators mostly use the left hand for lifting and maneuvering chainsaw. As a result, these movements affect the musculoskeletal system in the left upper arm, left forearm, and left hand. Different work postures require the use of different parts of the body, and in the end, lead to different MSDs consequences.

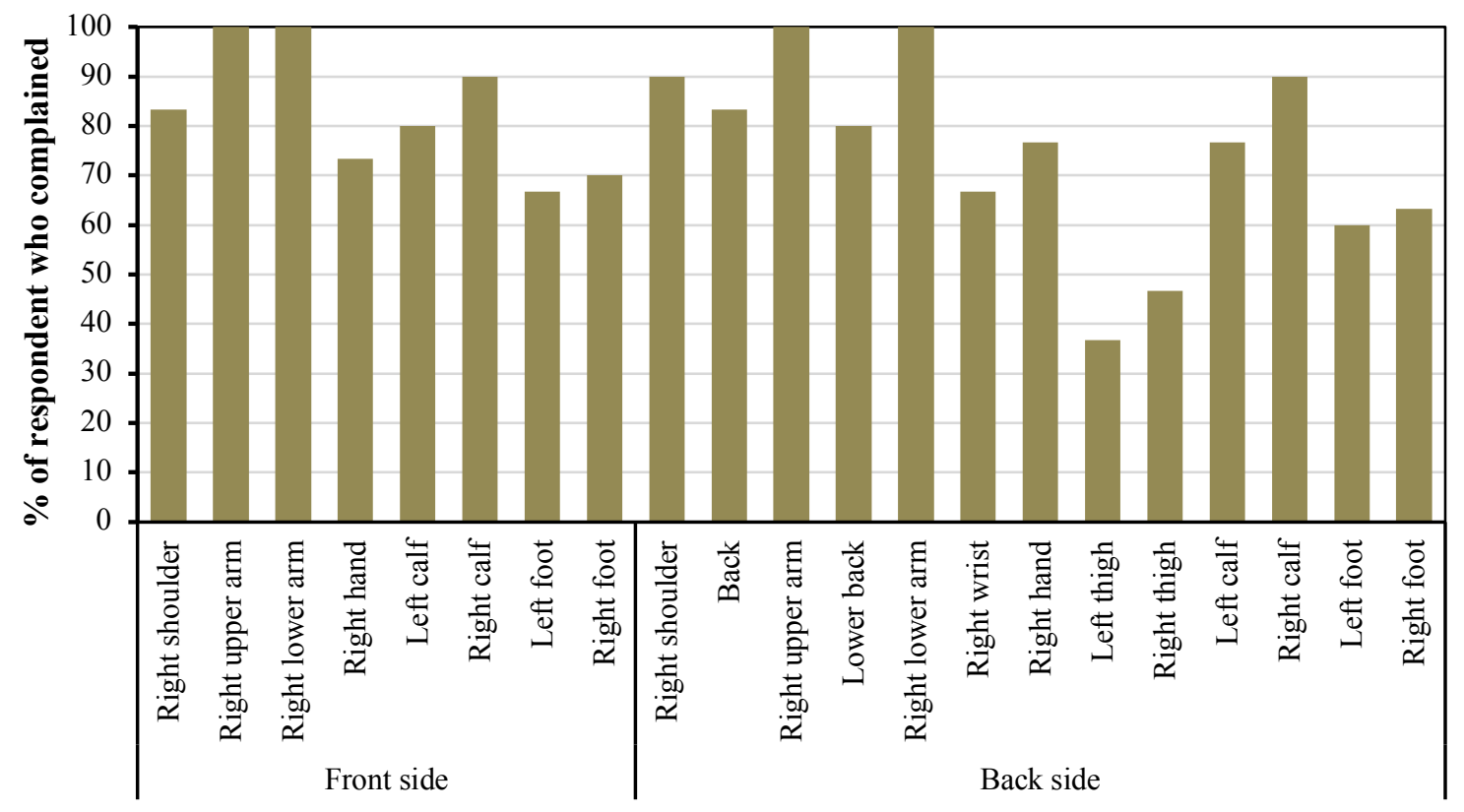

Figure 3. MSDs distribution among the workers. 

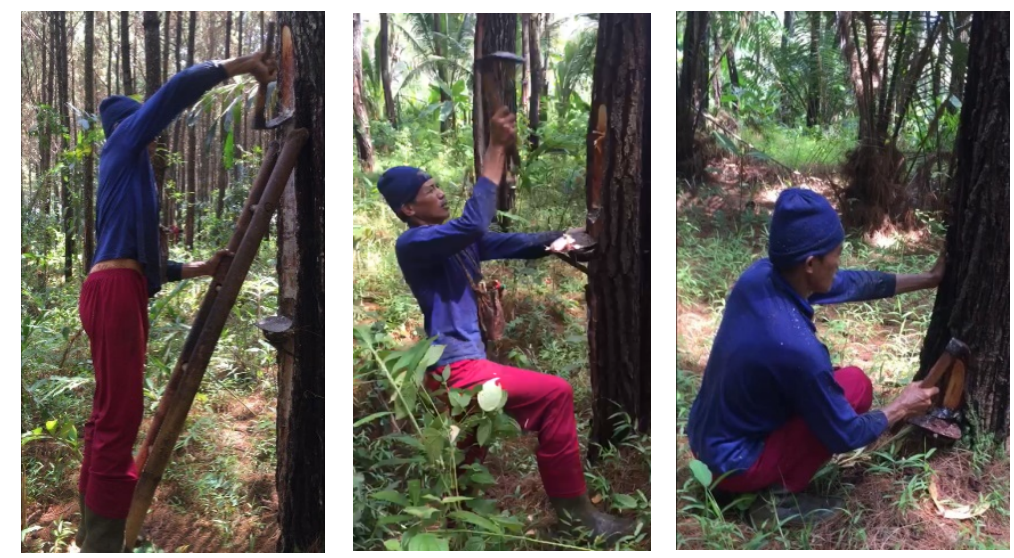

Figure 4. Several tapping postures. Postures vary greatly depending on the height of the tapping location.

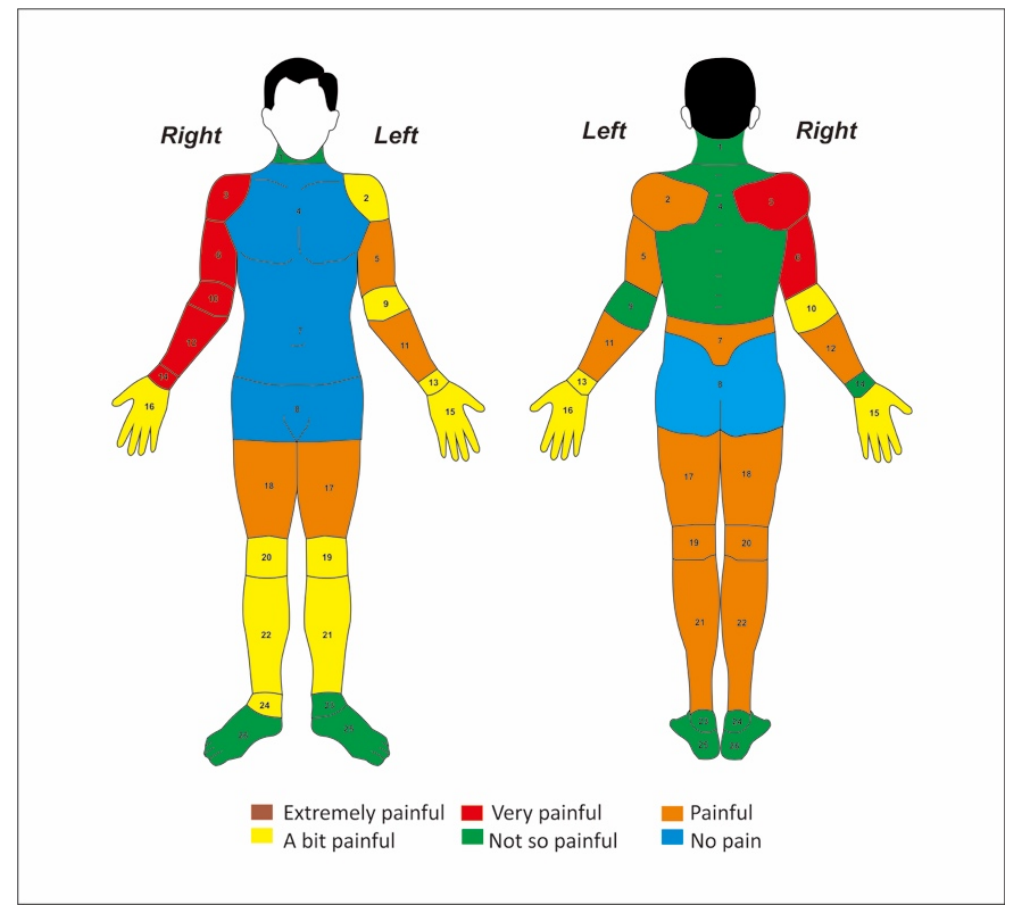

Sources: Modified from Kuorinka et al. (1987)

Figure 5. Distribution of body pain among the workers.

\section{Cumulative Fatigue Symptom}

Fatigue is a complex phenomenon and is a multidimensional concept. Its triggers factors and effects overlap the areas of physical, physiology, cognitive, emotion, and even social. Many studies have consistently shown that fatigue impairs cognitive functioning and behavioral motor performance (Neu et al. 2011), which lead to error and accidents. Therefore, we consider that it is essential to understand the status of fatigue among Indonesian forestry workers.

Most of the workers experienced physical fatigue in all subdimensions: general fatigue (61\%), chronic fatigue (59\%), and physical disorders (50\%) (Figure 6), and showed light mental and social fatigue. The common symptoms for general fatigue syndrome were shoulder stiffness, backache, joint pain, and experiencing weakness (asthenia). The workers also stated they were too sleepy and feeling tired all the time, even after they take some rest, where all of these symptoms refers to chronic fatigue. The intense symptoms of physical disorders experienced 
by most workers were excessive worries about their health associated with a heavy head. In terms of the mental dimension, the most dominant complaint is in the subdimension of depressive feelings, which is reflected in the great desire to do recreation to escape from their problems. In general, the distribution of fatigue symptoms in the tapping workers is similar to that of chainsaw operators, helpers, logging truck drivers, and hauling workers (Yovi and Yamada 2019). These groups of workers are field workers who use the physical while doing their work. It should be noted that different situations occurred in forest inventory workers who have a high anxiety disorder (Yovi 2019). The work location and work characteristics among inventory workers seem to be a determining factor for the occurrence of severe mental fatigue symptoms.

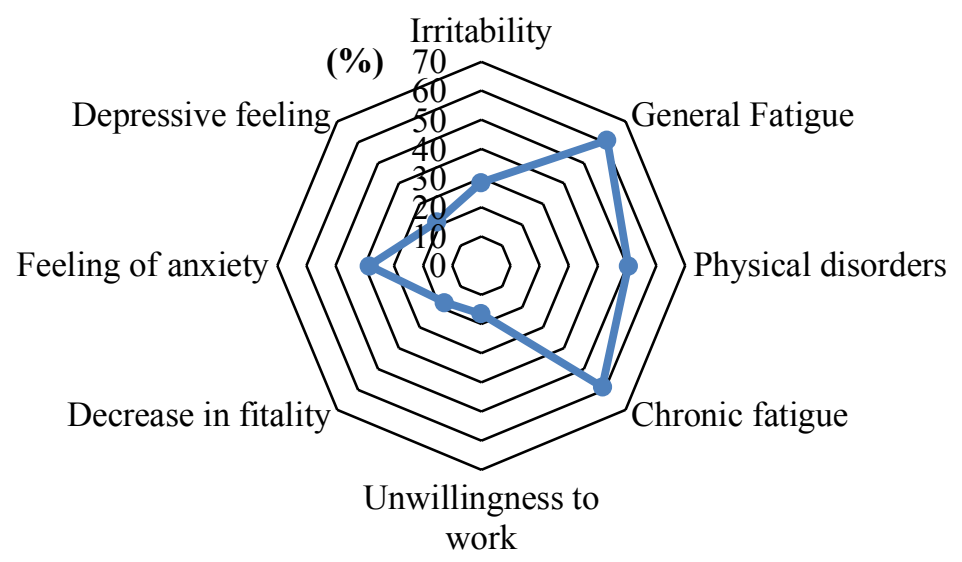

Figure 6. Cumulative fatigue symptoms experienced by the workers.

\section{Job Satisfaction}

As is discussed in the previous segments, work in the forest brings significant pressures. These job stressors relate negatively to job performance (Arshadi and Damiri 2013) and are detrimental not only to individual health and work productivity (Shobe 2018) but also to safety (Strahan et al. 2008). On the other side, good job satisfaction associated with higher safety commitment (Barling et al. 2003; Gyekye 2005; Probst and Brubaker 2001).

The reliability test showed a high Cronbach's $\alpha(0.862)$ and McDonald's $\omega(0.877)$. The data were normally distributed (Shapiro-Wilk $p<0.001$ ). Associative tests (Rank Spearman) that were carried out on each variable showed that among the variables, wages and contract status have a significant association (positive) with job satisfaction $(\alpha=0.05$; Spearman's rho is 0.390 and 0.577 , respectively).

The test results indicate that in the context of wages, the higher the wage, the greater the job satisfaction level. Interesting findings were found in the employment status variable. Interview with workers indicates that seasonal work contracts give opportunities to do other economic activities, such as farming, raising livestock, and running small grocery stores. The wage/income from this work is half of their monthly financial income. This finding is contrary to the result of a similar study carried out to contract workers in the operator/equal level, i.e., chainsaw operator, helper, logging truck drivers, manual hauling workers, nursery workers, and tractor operator (Yovi and Yamada 2019). This group of workers expects their contract status to become permanent employees. The finding that being permanent workers is associated with high job satisfaction also has been verified in another study carried out to permanent workers. This study confirmed that status as permanent workers related to a high level of job satisfaction (Yovi 2019). It seems that the level of dependency on forestry work to make a living, which is quite high in these two previous studies ( $80-100 \%$ of monthly income derived from forestry work), is the reason behind different employment status preferences. 


\section{Occupational Safety and Health (OSH) Protection Strategy}

This study offers a picture of the working conditions in pine oleoresin extraction activities from physical and cognitive ergonomics standpoints. Improvement strategy should be put into serious consideration. The improvement of OSH protection from technical aspects that need to be done is to complete PPE, improve working aids, and improve work techniques. For nontechnical aspects, the improvement that needs to be done is to increase the wage of the workers.

\section{PPE and workaid tools}

PPE is a hazard control technique having the lowest effectiveness (NIOSH 2018), but it is the easiest and most likely to be done. The provision of complete PPE needs to be done. With a low level of income from manual tapping, employers should provide the required PPE.

The next challenge is the habituation in using the PPE, as it refers to behavior shifting. Behavior shifting is a complex and not an instant process because it involves elements of capability (physical and psychological), opportunity (physical and social), and motivation (automatic and reflective) (Michie et al. 2011). To overcome this, a potential approach that can be put in the employer's consideration is offering incentives in the form of financial rewards (Forsythe and Venter 2019). At the same time, the workers should acquire the safety aspect of pine tapping. Because of the literacy limitation, learning can be done in game-based learning, which has proven to be very effective in increasing the level of knowledge for forestry workers (Yovi and Yamada 2015).

In the context of workaid tools, the design of the kadukul should be improved, as the handle's design could not support a firm and strong handhold (Figure 1b). Therefore it is necessary to add rubber pads to the grip that will increase friction and increase the grip strength so that kadukul does not slip easily.

\section{Working technique}

In working techniques, it is important to improve work instructions, especially the "may and may not be done." The tapping height should be set clearly and firmly. Included in the improvement of work techniques is providing clear work technical guidelines governing PPE and workaid tools.

\section{Wage}

Tapping work contributes $50 \%$ of the worker's total monthly income, while this work takes longer work time compared to farming, breeding livestock, or running a small grocery store. One cycle of pine oleoresin extraction consists of three times refreshing and one time collecting that go to this order: refreshing-refreshing-refreshing-collecting with three days intervals between each activity. If a worker holds a tapping right for three different areas (which is quite common), he will work almost every day, 6 hours per day (average), and allocate the remaining time for non-forestry works to make a living. This work time allocation indicates that for almost the same amount of income, the workers spend a long time tapping than for the non-forestry work. The fact that the resin extraction is stopped during the rainy season toughen worker's perception that tapping jobs are less economically promising than their other occupation.

There is a strong need to raise the wage/income of the worker To increase safety in pine oleoresin extraction, as there is a positive and strong relationship between the amount of wage and job satisfaction. Job satisfaction has been confirmed as an important element in the safety behavior (Barling et al. 2003; Gyekye 2005; Probst and Brubaker 2001). In this attempt, wage increases will satisfy the workers. 
The increment could be given in the form of safe behavior incentive, where a certain amount of money should be awarded to workers who keep the safety rule. This way, the workers will be satisfied with the higher income, and on the other side, employers will achieve success in promoting safe work behavior in the workplace (Forsythe and Venter 2019).

\section{CONCLUSIONS}

Even though reports of fatalities in oleoresin extraction is rarely found, this forestry work may threaten the worker's occupational safety and health. The protection of occupational safety and health is one of the fundamental human rights and, at the same time, crucial in the issue of sustainable forest management. This study focuses on ergonomics conditions on pine oleoresin extraction on physical and cognitive ergonomics, especially on MSDs, physical-mental-social fatigue, and job satisfaction. As the traditional tapping technique -which is a typical manual handling activity- discussed in this study are widely applied, this study findings can also be seen as a representation of other similar operations carried out all over Indonesia. This traditional oleoresin extraction caused MSDs on the upper limb's right side. For the lower limb, the MSDs were reported in the right and left legs (thighs, back of the knee, and calf) at various pain levels. In terms of fatigue, most of the workers experienced general fatigue, chronic fatigue, and physical disorders. Type of accidents ever occurred are hit by the tip of the kadukul/pethel's blade and hit by a splinter of pine barks. The finding explicitly shows that OSH threats in this activity do exist. Therefore, an OSH protection strategy is required. A job satisfaction analysis indicates that increasing wages may increase job satisfaction, and in the end, will increase individual safety behavior.

\section{REFERENCES}

Arshadi, N., and Damiri, H. 2013. The Relationship of Job Stress with Turnover Intention and Job Performance: Moderating Role of OBSE. in: Procedia - Social and Behavioral Sciences 706-710. DOI: 10.1016/j.sbspro.2013.06.631

Barling, J., Kelloway, E. K., and Iverson, R. D. 2003. High-Quality Work, Job Satisfaction, and Occupational Injuries. The Journal of applied psychology 88(2): 276-283. DOI: 10.1037/0021-9010.88.2.276

Bhattacharya, A. 2014. Costs of Occupational Musculoskeletal Disorders (MSDs) in the United States. International Journal of Industrial Ergonomics 44(3): 448-454. DOI: 10.1016/j.ergon.2014.01.008

BPS. 2011. Statistics of Forest Concesion Estate 2010. BPS (Statistics Indonesia), Jakarta, Indonesia.

BPS. 2016. Statistics of Forest Concesion Estate 2015. BPS (Statistics Indonesia), Jakarta, Indonesia.

BPS. 2018. Statistics of Forest Concesion Estate 2017. BPS (Statistics Indonesia), Jakarta, Indonesia.

Chaffin, D. B., Andersson, G. B. J., and Martin, B. J. 2006. Occupational Biomechanics, 4th Edition. Wiley-Blackwell.

Chen, J., Mu, X., and Du, F. 2017. Biomechanics Analysis of Human Lower Limb During Walking for Exoskeleton Design. Journal of Vibroengineering 19(7): 5527-5539. DOI: $10.21595 /$ jve.2017.18459

Collins, J. D., and O'Sullivan, L. W. 2015. Musculoskeletal Disorder Prevalence and Psychosocial Risk Exposures by Age and Gender in A Cohort of Office Based Employees 
in Two Academic Institutions. International Journal of Industrial Ergonomics 46: 85-97. DOI: 10.1016/j.ergon.2014.12.013

Cunningham, A. 2012. Pine Resin Tapping Techniques Used Around the World. in: Pine Resin: Biology, Chemistry and Applications A. G. Fett-Neto and K. C. S. Rodrigues-Corrêa, eds. Research Signpost, Kerala, India 1-8.

Ferguson, S. A., Allread, W. G., Le, P., Rose, J., and Marras, W. S. 2013. Shoulder Muscle Fatigue During Repetitive Tasks as Measured by Electromyography and Near-Infrared Spectroscopy. Human Factors 55(6): 1077-1087. DOI: 10.1177/0018720813482328

Forsythe, A. M., and Venter, C. 2019. Behavioral Economics, Motivating Psycho-Education Improvements: A Mobile Technology Initiative in South Africa. Frontiers in Psychology 10: 1560. DOI: 10.3389/fpsyg.2019.01560

Garra, G., Singer, A. J., Taira, B. R., Chohan, J., Cardoz, H., Chisena, E., and Thode, C. H. J. 2010. Validation of the Wong-Baker FACES Pain Rating Scale in Pediatric Emergency Department Patients. Academic Emergency Medicine 17(1): 50-54. DOI: 10.1111/j.1553-2712.2009.00620.x

Guan, W. J., Zheng, X. Y., Chung, K. F., and Zhong, N. S. 2016. Impact of Air Pollution on the Burden of Chronic Respiratory Diseases in China: Time for Urgent Action. The Lancet 388(10054): 1939-1951. DOI: 10.1016/S0140-6736(16)31597-5

Gyekye, A. S. 2005. Workers Perceptions of Workplace Safety and Job Satisfaction. International Journal of Occupational Safety and Ergonomics 11(3): 291-302. DOI: 10.1080/10803548.2005.11076650

Hansen, C. D., Rasmussen, K., Kyed, M., Nielsen, K. J., and Andersen, J. H. 2012. Physical and Psychosocial Work Environment Factors and Their Association with Health Outcomes in Danish Ambulance Personnel - A Cross-Sectional Study. BMC Public Health 12(534): 13. DOI: 10.1186/1471-2458-12-534

Hrymak, V., and Pérezgonzález, J. D. 2007. The Costs and Effects of Workplace Accidents Twenty Case Studies from Ireland. Health and Safety Authority, Ireland.

Huysamen, K., de Looze, M., Bosch, T., Ortiz, J., Toxiri, S., and O’Sullivan, L. W. 2018. Assessment of an Active Industrial Exoskeleton to Aid Dynamic Lifting and Lowering Manual Handling Tasks. Applied Ergonomics 68: 125-131. DOI: 10.1016/j.apergo.2017.11.004

Kahraman, T., Genç, A., and Göz, E. 2016. The Nordic Musculoskeletal Questionnaire: CrossCultural Adaptation Into Turkish Assessing its Psychometric Properties. Disability and Rehabilitation 38(21): 2153-2160. DOI: 10.3109/09638288.2015.1114034

Karwowski, W., and Marras, W. S. 2003. Occupational Ergonomics: Principles of Work Design. CRC Press, Boca Raton, Florida.

Kosugo, R., and Fujii, H. 1987. An Index for Rating Cumulative Fatigue Symptoms (CFSI) in Different Occupations. Journal Science of Labour 63(5): 229-246.

Kosugo, R., Fujii, H., and Hirata, A. 1992. Subjective Assessment of Workload. (1). Revision of the Cumulative Fatigue Symptoms Index. Journal Science of Labour 68(10): 489-502.

Kroemer, K., and Grandjean, E. 1997. Fitting the Task to the Human, Fifth Edition. CRC Press, London, UK. DOI: 10.1201/b16825

Kumar, S. 2001. Theories of Musculoskeletal Injury Causation. Ergonomics 44(1): 17-47. DOI: $10.1080 / 00140130120716$

Kuorinka, I., Jonsson, B., Kilbom, A., Vinterberg, H., Biering-Sørensen, F., Andersson, G., and Jørgensen, K. 1987. Standardised Nordic Questionnaires for the Analysis of Musculoskeletal Symptoms. Applied Ergonomics 18(3): 233-237. DOI: 10.1016/00036870(87)90010-X

Lindroos, O., and Burström, L. 2010. Accident Rates and Types Among Self-Employed Private Forest Owners. Accident Analysis and Prevention 42(6): 1729-1735. DOI: 
10.1016/j.aap.2010.04.013

López-Aragón, L., López-Liria, R., Callejón-Ferre, ángel J., and Gómez-Galán, M. 2017. Applications of the Standardized Nordic Questionnaire: A Review. Sustainability 1514: 1514. DOI: $10.3390 /$ su9091514

Michie, S., van Stralen, M. M., and West, R. 2011. The Behaviour Change Wheel: A New Method for Characterising and Designing Behaviour Change Interventions. Implementation Science 6(42). DOI: 10.1186/1748-5908-6-42

Neu, D., Kajosch, H., Peigneux, P., Verbanck, P., Linkowski, P., and Le Bon, O. 2011. Cognitive Impairment in Fatigue and Sleepiness Associated Conditions. Psychiatry Research Elsevier 189(1): 128-134. DOI: 10.1016/j.psychres.2010.12.005

NIOSH. 2018. Hierarchy of Control. National Institute for Occupational Safety and Health (NIOSH). <https://www.cdc.gov/niosh/topics/hierarchy/default.html>.

Potočnik, I., Pentek, T., and Poje, A. 2009. Severity Analysis of Accidents in Forest Operations. Croatian Journal of Forest Engineering 30(2): 171-184.

Probst, T. M., and Brubaker, T. L. 2001. The Effects of Job Insecurity on Employee Safety Outcomes: Cross-Sectional and Longitudinal Explorations. Journal of Occupational Health Psychology 6(2): 139-159. DOI: 10.1037//1076-8998.6.2.139

Sakka, S., Chablat, D., Ma, R., and Bennis, F. 2015. Predictive Model of the Human Muscle Fatigue: Application to Repetitive Push-Pull Tasks with Light External Load. International Journal of Human Factors Modelling and Simulation 5(1): 81-97. DOI: 10.1504/ijhfms.2015.068124

Shobe, K. 2018. Productivity Driven by Job Satisfaction, Physical Work Environment, Management Support and Job Autonomy. Business and Economics Journal 9(2): 1-9. DOI: $10.4172 / 2151-6219.1000351$

Strahan, C., Watson, B., and Lennonb, A. 2008. Can Organisational Safety Climate and Occupational Stress Predict Work-Related Driver Fatigue? Transportation Research Part F: Traffic Psychology and Behaviour 11(6): 418-426. DOI: 10.1016/j.trf.2008.04.002

Tsioras, P. A., Rottensteiner, C., and Stampfer, K. 2014. Wood Harvesting Accidents in the Austrian State Forest Enterprise 2000-2009. Safety Science 62: 400-408. DOI: 10.1016/j.ssci.2013.09.016

Wiegmann, D., Faaborg, T., Boquet, A., Detwiler, C., Holcomb, K., and Shappell, S. 2005. Human Error and General Aviation Accidents: A Comprehensive, Fine-Grained Analysis Using HFACS. Washington, DC.

Yoshimura, T., and Acar, H. H. 2004. Occupational Safety and Health Conditions of Forestry Workers in Turkey. Journal of Forest Research 9(3): 225-232. DOI: 10.1007/s10310004-0078-y

Yovi, E., Takimoto, Y., Ichihara, K., and Matsubara, C. 2005. Factors Affecting Workload and Work Efficiency in Pine Resin Harvesting Operations in Java's Plantation Forests. Journal of The Japan Forest Engineering Society 20(3): 141-150. DOI: 10.18945/jjfes.KJ00007485372

Yovi, E. Y. 2019. Status Ergonomi Pekerja Sektor Kehutanan di Indonesia: Kelelahan FisikMental-Sosial, Kepuasan Kerja, Konsep Sumber Bahaya, dan Konsep Biaya Kecelakaan. Jurnal Ilmu Kehutanan 13(2): 137-150. DOI: 10.22146/jik.52140

Yovi, E. Y., and Andriyani, L. E. 2019. Analisis Postur Kerja dalam Operasi Pemanenan Kayu: Pemuatan Log Secara Manual. Jurnal Ilmiah Teknik Industri 18(2): 170-182. DOI: 10.23917/jiti.v18i2.8727

Yovi, E. Y., and Prajawati, W. 2015. High Risk Posture on Motor-Manual Short Wood Logging System in Acacia mangium Plantation. Jurnal Manajemen Hutan Tropika (Journal of Tropical Forest Management) 21(1): 11-18. DOI: 10.7226/jtfm.21.1.11

Yovi, E. Y., and Yamada, Y. 2015. Strategy to Disseminate Occupational Safety and Health 
Information to Forestry Workers: The Felling Safety Game. Journal of Tropical Forest Science 27(2): 213-221.

Yovi, E. Y., and Yamada, Y. 2019. Addressing Occupational Ergonomics Issues in Indonesian Forestry: Laborers, Operators, or Equivalent Workers. Croatian Journal of Forest Engineering 40(2): 351-363. DOI: 10.5552/crojfe.2019.558 